\title{
«Генетический код» петербургской жилой среды (к 300-летию российских регулярных городских кварталов)
}

\author{
Л.П.Лавров, СПбГАСУ, Санкт-Петербург \\ Е.Г.Молоткова, СПбГАСУ, Санкт-Петербург \\ Ф.В.Перов, СПбГАСУ, Санкт-Петербург
}

Учитывается, что концепции новых градостроительных нормативов для РФ и Москвы, которые прорабатываются в настоящее время, придают особое значение квартальной системе застройки. В этой связи предлагается обратить внимание на опыт Санкт-Петербурга, где гипподамова планировка в широком масштабе стала применяться впервые в России. Показано, что за прошедшие триста лет в историческом центре города на площади в тысячи гектаров сложилась плотная городская ткань, определить своеобразие которой пытаются ссылкой на «генетический код» Санкт-Петербурга. Предлагается конкретизировать это романтическое представление и зафиксировать установки, которые обеспечили целенаправленное развитие застройки города. Подчёркивается, что огромные внутриквартальные пространства Санкт-Петербурга к настоящему времени мало изучены - множество работ посвящены архитектурно-художественному образу представительных корпусов по лицевому фронту кварталов, а феномен внутриквартальной среды на прикладном уровне затронули только исследования 1970-х годов (А.В. Махровская, Г.Д. Платонов). Высказывается предположение, что именно ограниченность исходной информационной базы объясняет появление упрощённого представления об историческом центре Санкт-Петербурга как едином «средовом районе», присутствующего в нормативно-методических указаниях и в проектных концепциях. Предлагается провести архитектурноградостроительную инвентаризацию включённых в этот район кварталов, чтобы зафиксировать сложившиеся морфотипы ${ }^{1}$.

Ключевые слова: городская жилая среда, землепользование, морфотипы кварталов, пешеходно-транспортные коммуникации, инженерная подготовка территорий.

"Genetic code" of the St. Petersburg Residential Environment (to the 300th Anniversary of Russian Regular City Blocks)

L.P.Lavrov, SPSUACE, St. Petersburg

E.G.Molotkova, SPSUACE, St. Petersburg

F.V.Perov, SPSUACE, St. Petersburg

It is considered that the concepts of new urban planning standards for the Russian Federation and Moscow, which are currently being developed, attach particular importance to the quarterly development system. In this regard, it is

\footnotetext{
${ }^{1}$ Данная статья продолжает тему, затронутую в статье «Морфотипь кварталов исторического центра Санкт-Петербурга», опубликованной в № 4 журнала «Academia. Архитектура и строительство» за 2019 год.
}

proposed to pay attention to the experience of St. Petersburg, where the hippodamic layout on a large scale began to be used for the first time in Russia. It has been shown that over the past three hundred years in the historical center of the city on an area of thousands of hectares a dense urban fabric has developed, the uniqueness of which is tried to determine by referring to the "genetic code" of St. Petersburg. It is proposed to concretize this notion and consolidate conceptions that ensured the purposeful development of the city. It is emphasized that the huge intra-quarter spaces of St. Petersburg have been little studied to date - many works are devoted to the architectural and artistic image of representative buildings along the front of the quarters, and the phenomenon of the intra-quarter environment at the applied level was affected only by studies of the 1970 s (A.V. Makhrovskaya, G.D. Platonov). It is suggested that it is the limitedness of the initial information base that explains the appearance of a simplified view of the historical center of St. Petersburg as a single "environmental area", which is present in normative and methodological guidelines and design concepts. It is proposed to carry out an architectural and urban planning inventory of the blocks included in this area to fix the set morphotypes.

Keywords: urbanliving environment,land use, morphotypes of neighborhoods, pedestrian-transport communications, engineering preparation of territories.

\section{Введение}

Ведущиеся разработки современных градостроительных нормативов для РФ и Москвы придают особое значение квартальной системе застройки [1-3], а исторический центр Санкт-Петербурга может рассматриваться как экспериментальная площадка, где некоторые из обсуждающихся градостроительных идей были реализованы в массовом масштабе в XVIII-XIX веках и получили натурную апробацию.

Санкт-Петербург стал местом, где впервые в России при формировании городской застройки стали широко использоваться принципы регулярной планировки. Первый шаг сделал Пётр I, который в 1709 году собственноручно прорисовал прямоугольную сетку улиц на исполненном им эскизе столичного города на острове Котлин. Началом практического внедрения можно считать 1712 год, когда были очерчены прямоугольные жилые кварталы на южном берегу Невы в Московской (Литейной) части. С 1714 года гипподамова си- 
стема стала основой при освоении пустынного и обширного Васильевского острова. В XVIII веке прямоугольная сеть кварталов доминировала как в центральном ядре российской столицы, так и в её пригородах и предместьях.

Во второй половине XVIII века Комиссия о каменном строении Санкт-Петербурга и Москвы составляла планы развития для сотен городов России. Учитывая достоинства регулярной гипподамовой системы, которые выявила практика Петербурга, в проектных решениях провинциальных городов стали повсеместно использоваться кварталы чётких прямоугольных очертаний. Помимо прочего, это соответствовало профессиональному потенциалу специалистов российской глубинки, где градостроительную деятельность осуществляли уездные землемеры, не всегда обладавшие высокой квалификацией.

B начале XIX века условия развития Санкт-Петербурга изменились. Возросли темпы строительства, многократно расширились масштабы. Считают, что «основная застройка ИЦ сформирована капитальными многоэтажными домами постройки второй половины XIX - начала XX вв.»². Их образ определили новые детерминанты - возросло воздействие коммерческих аспектов на землепользование и типологию среды, а роль прямого администрирования сократилась.

Формирование городской среды в историческом центре Санкт-Петербурга «завершилось (или оборвалось) сто лет назад, после чего она не подвергалась кардинальным изменениям» [4]. Ареал строительной деятельности советского периода лежал в пригородной зоне, а преобразования центра были незначительны и локальны. Проведение рыночных реформ, возникновение рынка недвижимости и динамичные структурные преобразования повысили урбанизационные нагрузки на центр и приковали внимание к его внутриквартальным ресурсам. Однако пока значительных реальных практических шагов в этом направлении не последовало - отсутствует информация, необходимая для прокладки дорожной карты. Предлагается рассмотреть материалы, которые помогут

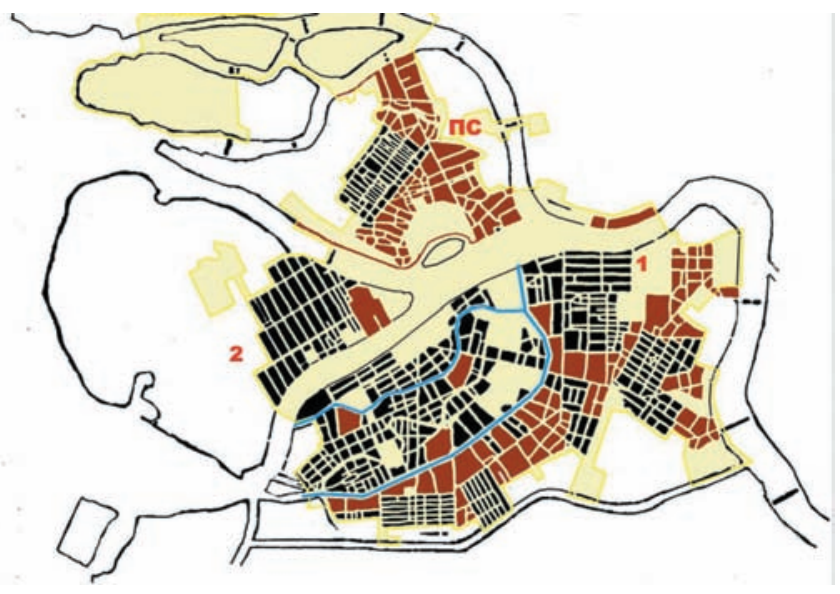

Pис. 1. Жилые кварталы исторического центра СанктПетербурга: 1 - Московская (Литейная) часть; 2 - Васильевский остров; ПС - Петроградская сторона. Голубыми линиями обозначены реки Мойка и Фонтанка приблизиться к рассмотрению ситуации на прикладном уровне, определить возможности и условия реализации лозунга «совершенствуя, не разрушать» [5].

\section{«Terra incognita» внутриквартальной среды Санкт- Петербурга}

Санкт-Петербург относится к числу тех российских городов, архитектурно-градостроительные особенности которых с давних пор являются объектом постоянного и заинтересованного внимания широкой публики и профессиональных исследователей. При этом сильно различается уровень изученности составляющих его элементов. Детально обследованы открытые общественные пространства города и тысячи исторических построек, которые формируют улицы и площади. Под государственной охраной состоят 7783 объекта культурного наследия - архитектурные ансамбли, здания и инженерные сооружения, сады и парки, пруды и каналы, монументальная и садово-парковая скульптура, исторические захоронения и археологические объекты. Обширные внутриквартальные пространства остались в тени. Детальные архитектурные исследования внутриквартальной застройки проводились только в 1970-е годы, но они затронули лишь часть проблем [6; 7]. Территории площадью в несколько тысяч гектаров в центре крупнейшей метрополии привлекают внимание коммунальных и кадастровых служб, спекулянтов недвижимостью, но для архитекторов остаются «терра инкогнита». У градостроителей и специалистов по охране памятников имеется лишь самое общее представление о рядовой городской ткани, не выявлены и не оценены её конкретные составляющие. Соответственно этому и «предметами охраны культурного наследия являются характер среды, включающий планировочный модуль кварталов и участков, масштаб, высотность и членение застройки» ${ }^{3}$.

Перечисленные положения позволяют разделить жилую среду города на две части, которые на рисунке 1 выделены разными цветами: черным - участки с регулярной сетью прямоугольных кварталов, коричневым - территории, где преобладают кварталы большой площади, лишённые столь чётких очертаний.

Ключом к объяснению такого дифференцирования могут быть сведения из «генетического кода» Санкт-Петербурга.

\section{«Генетический код»}

Два десятилетия назад в профессиональный язык было введено понятие «петербургский генетический код» и дана

2 TСН 30-306-2002, Территориальные строительные нормы. Реконструкция и застройка исторически сложившихся районов Санкт-Петербурга. - СПб : Стройиздат СПб, 2003. - 71 с.

${ }^{3} 0$ Петербургской стратегии сохранения культурного наследия. Постановление Правительства Санкт-Петербурга от 1 ноября 2005 года № 1681 [Электронный ресурс] // Электронный фонд правовой и нормативно-технической документации. - Режим доступа: docs.cntd.ru/document/8421327 (дата обращения 10.09.2019). 
трактовка его влияния на стратегию градостроительного развития Санкт-Петербурга [8]. Можно утверждать, что этот «генетический код» проявил себя и на локальном уровне во многих направлениях архитектурно-градостроительной деятельности, в том числе - при формировании массовой рядовой жилой застройки

Санкт-Петербург относится к числу «спланированных городов». Реализацию предписанной регулярной градостроительной модели вели частные застройщики, но их действия регламентировались и направлялись в очерченное русло административными указаниями. Базовые положения, определённые Петром I и Д. Трезини, на протяжении двух столетий были организационно-методической основой проектно-строительного комплекса. Роль этого методического наследия невозможно переоценить. «Петербург, оставленный Петром Великим, был слишком бедный и ничтожный городок, чтоб о нём можно было говорить, как о чём-то важном. Казалось, этому городку, обязанному своим насильственным существованием воле великого человека, не суждено было пережить своего строителя... Но здесь-то и является во всём блеске творческий гений Петра Великого: его планы, его предначертания должны были продолжаться вековечно», - писал В.Г. Белинский [9].

Базовые положения, установленные в начале XVIII века, с течением времени уточнялись и конкретизировались. Были периоды, когда от некоторых деталей временно отступали, но решающая роль ключевых установок неоднократно подтверждалась. Их можно перечислить:

А - систему землепользования Санкт-Петербурга предопределяли администативные решения. На этапе начального освоения «ничьей» земли застройщики бесплатно получали участки для застройки. Земельный рынок проявил себя позже, а обязательный налог на землю ввели лишь в 1801 году [8].

В.1 - первичным и стабильным элементом градостроительной системы Санкт-Петербурга является участок застройки («домовой участок», парцелла). С петровских времен не допускались разделение участков и продажа земли по частям (возможно было только слияние соседних участков). Стабильность межевания на протяжении двух столетий была стержнем градостроительного развития города. СанктПетербург рос, осваивал свободные земли, предместья становились городскими районами. На месте деревянных и мазанковых домов возводились кирпичные, потом они надстраивались. Во дворах вместо капустных грядок появлялись утилитарные блоки дешевых квартир, но границы очерченных ранее парцелл оставались неизменными. Некоторые послабления этой системы были допущены только в конце XIX века. Сейчас традиционный «планировочный модуль кварталов и участков... членение застройки» признаны составной частью культурного наследия города 4 .

В.2 - участок застройки имеет прямоугольные очертания, регламентируемые габариты и чётко выделен по границам (сначала - заборами, затем пограничными постройками и глухими брандмауэрами). Можно считать, что прототипом парцеллы в форме прямоугольника был участок застройки усадьбы А. Меншикова (ныне - городской квартал № 2006), габариты которого были чётко очерчены в 1714 году и показаны на обмерной карте Васильевского острова5. Тогда эта парцелла огромных размеров (примерно $400 \times 800$ м) была единственной освоенной площадкой в центральной части города. С 1720-х годов межевание прямоугольных парцелл стало обязательным для городских жилых кварталов [10].

В.3 - унификация габаритов земельных участков. Вопрос о габаритах возник в 1720-е годы при межевании площадок вдоль берега Невы, где строились представительные «дома для именитых». Решили учесть опыт возведения 2-5-этажных элитных домов на берегу канала Херренграхт в Амстердаме во второй половине XVII века. Голландский рынок недвижимости определил, что в таких условиях рациональны участки шириной 6-9 метров [11]. В Санкт-Петербурге земля ещё была «ничьей», только обретала рыночную стоимость, почвы были слабее амстердамских, а строительные технологии ограничивали высоту зданий, поэтому размеры участков «для именитых» на берегу Невы приняли увеличенными по сравнению с амстердамскими (5-10 сажен по фасаду). Такие нормативы межевания, установленные Петром I, впоследствии сочли недостаточными, поскольку большинство горожан занимались садоводством и огородничеством. С 1738 года на Адмиралтейской стороне стали нарезать участки габаритами $(31,85 . .34,1) \times 63,9$ м. Габариты участков были унифицированы и определялись их расположением в конкретном городском районе или в предместье. Для пригородных дач допускались участки непрямоугольной формы [10].

C - непрерывность и однородность фронта застройки вдоль красных линий квартала. Начало этому было положено при Петре, когда городские дома были деревянными или мазанковыми. После пожаров 1736-1737 годов, когда выгорела вся Морская слобода в Адмиралтейской части, «сплошной фронт фасадов» сочли неподходящим. В 1760-е годы город взял курс на каменное строительство, необходимость «сплошного фасада» была подтверждена и дополнена требованием о соблюдении единой высоты построек по всему фронту квартала: «Все домы, в одной улице состоящие, до самого ея пересечения в линию не выступая крыльцами в улицу одной сплошной фасадной и вышиной построены были» (по [12]). Строительство с отступом от красной линии появилось лишь на рубеже XIX и XX веков.

\footnotetext{
4 Постановление Правительства Санкт-Петербурга от 1 ноября 2005 года № 1681 «0 Петербургской стратегии сохранения культурного наследия» [Электронный ресурс] // Электронный фонд правовой и нормативно-технической документации. - Режим доступа: docs.cntd.ru/document/8421327 (дата обращения 10.09.2019).

5 Леспинас. План Васильевского острова, 1714 г. ЦГАВМФ. Ф. 3-«Л». 0п. 34. Д. 2465.
} 
D - регулирование высоты построек. В связи с докладом Комиссии строений от 8/II 1765 г. сочли необходимым увеличить высоту застройки на набережных до 10 сажен (примерно 21,3 м), чтобы «строение по Неве хотя мало соответствовало созидаемому по сей реке каменному берегу» (по [12]). В 1844 году ограничили допустимую высоту гражданских построек [13]. Некоторые послабления наступили в конце XIX века, но они проявились на перферии центра. С середины 1990-х годов генетический код теряет силу, и горизонтальный силуэт исторического ядра начинает деформироваться. На центральных улицах над фасадной линией карнизов, которые ещё выдерживали отметку «не выше 24 метров», начали вздуваться мансарды, а в глубине кварталов были разрешены постройки высотою до 28-40 метров [14].

E - принципиальные различия в формировании лицевой и внутриквартальной застройки. Деятельность застройщиков по совершенствованию и украшению корпусов, оформляющих красную линию квартала, получала поддержку, а на внутриквартальных территориях до 1830-х годов ориентировались на невысокую интенсивность использования пространства.

\section{Этапы эволюции «генетического года»}

Различия, зафиксированные на рисунке 1, отражают особенности двух этапов землепользования: уникальные возможности первичного освоения «ничьей земли» были определяющими в 1703-1820-е годы. Государство без ограничений распоряжалось судьбой пустынных непривлекательных территорий. Административными решениями диктовались и трассировка улиц, и принципы межевания внутриквартальных территорий. Габариты участков в пределах городской черты отличались от установленных для пригородных зон. В предместьях выделяли площадки для полковых городков, слобод дворцовых служителей, для крупных поместий, нарезались огородные участки, размещались кладбища и скотобойни $[10,15]$. Важную роль в становлении гипподамовой планировочной системы играли местные почвенные условия.
«Болота, древесина, вода» - определил детерминанты строительства на берегах Невы Д. Трезини [16]. В 1716 году Пётр I утверждает разработанные им чертежи, и работа по освоению Васильевского острова начинается. В 1717 году царю представляют столь ожидаемый им генеральный план новой российской столицы, который составил приглашённый из Парижа Ж.-Б. Леблон. Но этот проект не оказывает никакого влияния на развитие города: «Пётр Великий не воспользовался буквально ничем из плана Леблона и пренебрёг им, как и всей французской градостроительной теорией» [17]. Работы продолжаются по эскизам прагматичного и знающего местные условия Д. Трезини. Сохранилось письмо Петра I, адресованное А. Меншикову, которое касалось Васильевского острова. Речь шла о прокладке системы каналов и о возведении «домов для именитых» на прибрежной полоске с плотным грунтом [18]. Очевидно, что там уже шла инженерная подготовка территории, осушение насыщенных водою грунтов. Мелиоративных работ такого масштаба в России ещё не было. Использовали голландский опыт, разбили опорную прямоугольную сетку и начали откапывать дренажные каналы и канавы (рис. 2). Метод, использованный в петровскую эпоху, и сейчас используется при освоении заболоченных земель Петербурга и его окрестностей.

Прямоугольная сеть осушительных каналов, заложенных на этапе инженерной подготовки, органично перерастала в улично-дорожную систему городских районов и пригородных поселений. Генетический код проявил себя в период интенсивного каменного строительства (когда население, насчитывавшее в 1764 году примерно 150 тыс. человек, выросло до 470 тыс. в 1840 году) и определил образ исторического ядра города. Деревянные и мазанковые постройки уступали место кирпичным домам, повышалась плотность застройки, здания надстраивались, но границы участков застройки и красные линии кварталов на протяжении двух столетий оставались неизменными. Плотная и жёсткая городская ткань стала спокойным и строгим фоном для уникальных доминант
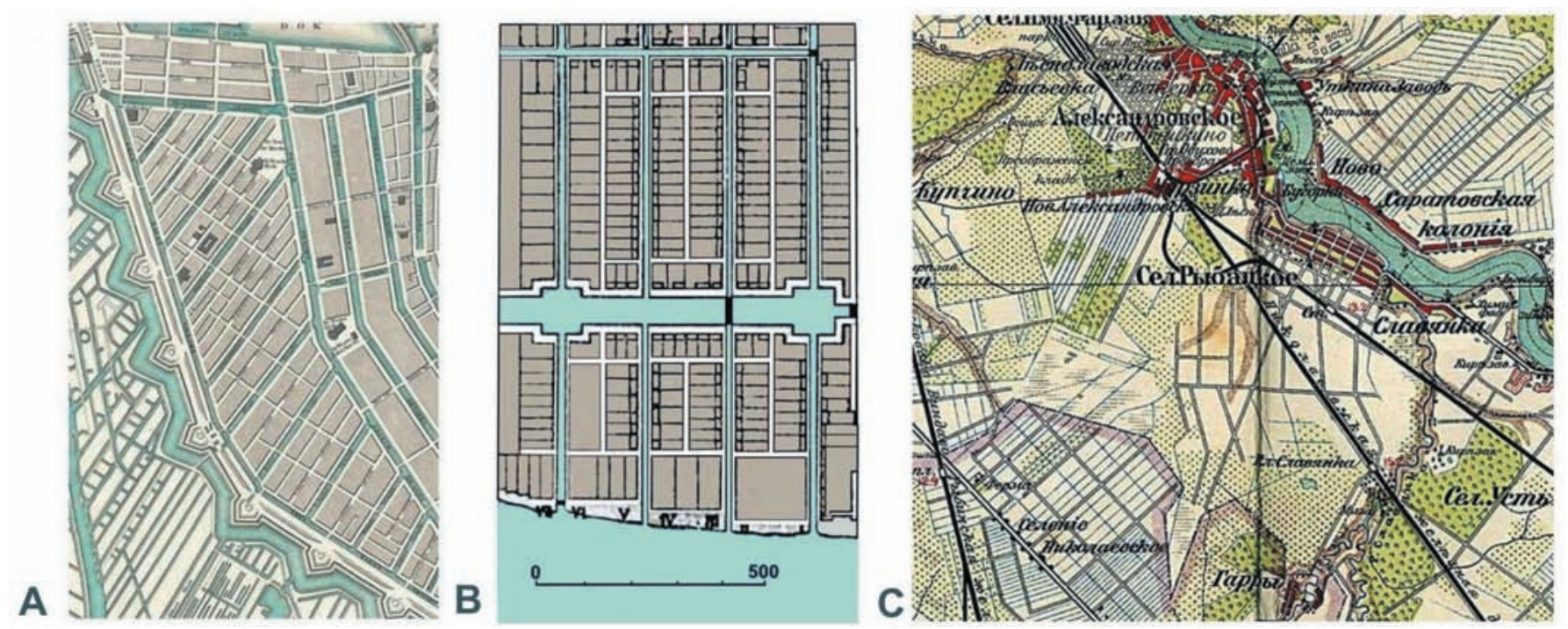

Рис. 2. Использование системы дренажных каналов 
и продуманно очертила общественные пространства - улицы и площади. Она контрастирует с живостью криволинейных рек и протоков, с открытым пространством невской акватории и выявляет архитектурно-художественное своеобразие СанктПетербурга. Этот образ соответствовал описанию морфотипа плотной городской застройки и представлял собой «экономную «решётчатую» планировочную структуру... однородное плотное, жёстко-структурное состояние» [19].

По мере территориального развития Санкт-Петербурга и поэтапного перемещения городской границы на юг жёсткость планировочных решений снижается. «Неправильная» форма кварталов на южном берегу Мойки объясняется не только живыми изгибами реки - в XIX веке изменились условия территориального расширения города. Резервы свободных земель в ближайшем окружении были исчерпаны. Новые жилые кварталы стали возводить в предместьях, где межевание было проведено в XVIII веке по нормативам пригородной зоны. Рядом с огромными массивами пригородных поместий были нарезаны участки под дачи, огородные плантации, кладбища, скотопригонные дворы и другие элементы коммунального обслуживания. Разнородные площадки обрели своих хозяев, и регулятором застройки становятся условия земельного рынка. Полагают, что и здесь «формирование или трансформация частей (фрагментов) города протекали целенаправленно и планомерно, а отнюдь не стихийно и хаотично» [20]. Однако в это время возможность административного воздействия на застройку уменьшилась, и характер жилой ткани на присоединенных к городу территориях стал определяться игрой цен на рынке недвижимости. Параметры кварталов, которые возникали с середины XIX века, отражают компромисс между новыми устремлениями и существовавшей c XVIII века схемой межевания. Участки, которые удавалось приобрести для освоения, редко имели чёткую прямоугольную форму, а трассы существовавших пригородных дорог не всегда были прямолинейными.

Процесс урбанизации требовал развития сети улиц и проездов, но сказывались и административно-юридические препоны, и недостаток городских средств на выкуп необходимых земельных участков. К градостроительной деятельности подключается частный капитал: люди заинтересованы в освоении под доходную застройку привлекательных площадок в оживлённых частях города. Тем не менее развитие транспортного каркаса Санкт-Петербурга, особенно на вновь присоединённых территориях, отставало от темпов территориального роста города. Кварталы больших размеров стали характерным признаком городской среды, сложившейся в 1840-1918 годы. К концу XIX века строительное законодательство преобразуется под воздействием рыночных отношений, и на осваиваемых территориях допускается разделение участков застройки, появляется возможность отступить от застройки «сплошным фасадом» вдоль красной линии, разрешают устраивать мансарды над карнизами. Развитие товарно-денежных отношений привело к изменению «генетического кода» в градостроительстве и архитектуре Санкт-Петербурга.

\section{Лumepamypa}

1. Приоритет - квартальной застройке [Электронный ресурс] // Archi.ru. - Режим доступа: https://archi.ru/ russia/50044/prioritet-kvartalnoi-zastroike (дата обращения 25.07.2019).

2. Матрица для квартальной застройки [Электронный ресурс] // Интерфакс-недвижимость. - Режим доступа: https://archsovet.msk.ru/pressa/elektronnye-smi/matricadlya-kvartal-noy-zastroyki (дата обращения 25.07.2019).

3. Жилая застройка [Электронный ресурс] // Data basis. - Режим доступа: http://www.data-basis.ru/images/doc/rffer-ter/main/0015_gor_standart_Kniga_1.pdf (дата обращения 25.07.2019)

4. Кириков, Б.М. Архитектура Петербурга-Ленинграда / Б.М. Кириков. - СПб : Коло, 2014. - 400 с.

5. Николащенко, Б.В. Двенадцать принципов практического градостроительства в Санкт-Петербурге от старожила улицы Зодчего Росси (памяти В.Ф. Назарова) [Электронный ресурс] / Б.В. Николащенко // Архитектурный Петербург - 2015. № 5. - Режим доступа: http://archpeter.ru/arkhiv/2015/05/ dvenadtsat-printsipov-prakticheskogo-gradostroitelstva-vsankt-peterburge-ot-starozhila-ulitsy-zodchego-rossi-pamjativf-nazarova/ (дата обращения 20.07.2019).

6. Махровская, А.В. Реконструкция старых жилых районов крупных городов (на примере Ленинграда) / А.В. Махровская. - Л. : Стройиздат, Ленингр. отделение, 1974. - 192 с.

7. Платонов, Г.Д. Типы домов и квартир для перспективного строительства в крупном городе (определение структуры жилищ с помощью ЭВМ на примере Ленинграда) : обзор / Г.Д. Платонов, И.Ю. Муравьева, Л.А. Ламекин. - М. : Изд-во ЦНТИ по гражданскому строительству и архитектуре, 1973. - 45 с.

8. Ружже, В.Л. Генетический код и парадоксы развития Петербурга / В.Л. Ружже // Санкт-Петербург на рубеже XX и XXI веков. - СПб : НИЦ «Экоград», 1999. - С. 89-130

9. Белинский, B. Петербург и Москва [Электронный ресурс] / В. Белинский // iknigi.net. - Режим доступа: http://iknigi. net/avtor-vissarion-belinskiy/49278-peterburg-i-moskvavissarion-belinskiy.html (дата обращения 26.03.2017)

10. Семенцов, С.В. Этапы формирования пространственной среды Санкт-Петербурга. Ч. 2. Историческое развитие участков (системы разбивки и застройки участков) и их регламентация. / С.В. Семенцов // Вестник гражданских инженеров. - 2006. - № 3 (8). - С. 21-26.

11. Глазычев, В.Л. Урбанистика. / В.Л. Глазычев. - М.: «Европа», 2008. - 220 с.

12. Бунин, А.В., Саваренская, Т.Ф. Выдающиеся русские города XVIII и начала XIX века. Петербург [Электронный ресурс] / А.В. Бунин, Т.Ф. Саваренская // Townevolution. ru. - Режим доступа: townevolution.ru/books/item/f00/s00/ z0000021/st040.shtml (дата обращения 16.06.2018)

13. 0 ограничении постройки в С. Петербурге высоких зданий и надстроек этажей на существующих зданиях // Полное собрание законов Российской империи, собрание 
второе. - СПб: Типография II отделения Собственной Его Императорского Величества канцелярии, 1845. - Т. XIX, отделение первое, 1844, № 18398. - С. 752-753.

14. Высотный СПБ [Электронный ресурс] // Коммерсант. ru. - Режим доступа: http://kommersant.ru/doc/2223512 (дата обращения 27.02.2017).

15. Семенцов, С.В. Этапы формирования пространственной среды Санкт-Петербурга. Ч.1. Историческое развитие кварталов и их регламентация. / С.В. Семенцов // Вестник гражданских инженеров. - 2006. - № 2 (7). - С. 15-20.

16. Самин, Д.К. 100 великих архитекторов / Д.К. Самин. - М. : Вече, 2013. - 592 с.

17. Швидковский, Д. Великий город Петра Великого / Д. Швидковский // Наше наследие. - 2003. - № 66. - С. 4-29.

18. Борисова, Е.А. Работы Доменико Трезини по планировке и застройке Стрелки Васильевского острова в Петербурге / Е.А. Борисова // Русское искусство века. Материалы и исследования. - М., 1973. - С. 20-37.

19. Кожаева Л.Б. Морфотипы застройки в теории и на практике / Л.Б. Кожаева // Архитектурный вестник. - 2011. - № 4. - С. 43-47.

20. Кириков, Б.М. Архитектура Петербурга конца XIX начала XX века: Эклектика. Модерн. Неоклассицизм / Б.М. Кириков. - СПб : Коло, 2008. - 448 с.

\section{References}

1. Prioritet kvartal'noj zastrojke [Priority - to quarterly development]. Archi.ru. Access mode: https://archi.ru/ russia/50044/prioritet-kvartalnoi-zastroike (accessed 25.07.2019).

2. Matritca dlya kvartal'noj zastrojki [The matrix for quarterly development]. Interfaks-nedvizhimost' [Interfax Real Estate]. Access mode: https://archsovet.msk.ru/pressa/elektronnyesmi/matrica-dlya-kvartal-noy-zastroyki (accessed 25.07.2019).

3. Zhilaya zastrojka [Residential development]. Access mode: http://www.data-basis.ru/images/doc/rf-fer-ter/ main/0015_gor_standart_Kniga_1.pdf (accessed 25.07.2019)

4. Kirikov B.M. Arkhitektura Peterburga-Leningrada [Architecture of St. Petersburg-Leningrad]. Saint-Petersburg, Kolo Publ., 2014, 400 p.

5. Nikolashchenko B.V. Dvenadtsat' printsipov prakticheskogo gradostroitel'stva v Sankt-Peterburge ot starozhila ulitsy Zodchego Rossi (pamyati V.F. Nazarova) [The twelve principles of practical urban development in St. Petersburg from an oldtimer of the street of the Architect Rossi (in memory of V.F. Nazarov)]. Architecturnyy Peterburg [Architectural Petersburg], 2015, no. 5. Access mode: http://archpeter.ru/arkhiv/2015/05/ dvenadtsat-printsipov-prakticheskogo-gradostroitelstva-vsankt-peterburge-ot-starozhila-ulitsy-zodchego-rossi-pamjativf-nazarova/ (Accessed 20.07.2019).

6. Makhrovskaya A.V. Rekonstruktsiya starykh zhilykh rayonov krupnykh gorodov (na primere Leningrada) [Reconstruction of old residential areas of large cities (on the example of Leningrad)]. Leningrad, Stroiizdat, 1974, 192 p.
7. Platonov G.D., Murav'yeva I.Yu., Lamekin L.A. Tipy domov i kvartir dlya perspektivnogo stroitel'stva $v$ krupnom gorode (opredeleniye struktury zhilishch s pomoshch'yu EVM na primere Leningrada) [Types of houses and apartments for prospective construction in a large city (determination of the structure of dwellings using computers using the example of Leningrad)], obzor. Moscow, TsNTI on civil engineering and architecture Publ., 1973, 45 p.

8. Ruzhzhe V.L. Geneticheskiy kod i paradoksy razvitiya Peterburga [Genetic code and paradoxes of the development of St. Petersburg]. Sankt-Peterburg na rubezhe XX i XXI vekov [St. Petersburg at the turn of the 20th and 21st centuries]. St. Petersburg, Ecograd Publ., 1999, pp. 89-130.

9. Belinskiy V. Peterburg i Moskva [Petersburg and Moscow]. iknigi.net. Access mode: http://iknigi.net/avtor-vissarionbelinskiy/49278-peterburg-i-moskva-vissarion-belinskiy.html (accessed 26.03.2017)

10. Sementsov S.V. Etapy formirovaniya prostranstvennoj sredy Sankt-Peterburga. Ch. 2. Istoricheskoe razvitie uchastkov (sistemy razbivki i zastrojki uchastkov) $\mathrm{i}$ ih eglamentatsiya [Stages of the formation of the spatial environment of St. Petersburg. Part 2. Historical development of sites (system of breakdown and development of sites) and their regulation]. Vestnik grazhdanskih inzhenerov [Bulletin of Civil Engineers], 2006, no. 3 (8), pp. 21-26.

11. Glazychev V.L. Urbanistika [Urban studies]. Moscow, Evropa Publ., 2008, 220 p.

12. Bunin A.V., Savarenskaya T.F. Vydayushchiyesya russkiye goroda XVIII i nachala XIX veka. Peterburg [Outstanding Russian cities of the 18th and early 19 th centuries. Petersburg]. Townevolution.ru. Access mode: townevolution.ru/books/item/ f00/s00/z0000021/st040.shtml (accessed 16.06.2018).

13. 0 ogranichenii postroyki v S. Peterburge vysokikh zdaniy i nadstroyek etazhey na sushchestvuyushchikh zdaniyakh [0n the restriction of the construction of tall buildings and floor superstructures in existing buildings in St. Petersburg]. Polnoye sobraniye zakonov Rossiyskoy imperii, sobraniye vtoroye [Complete collection of laws of the Russian Empire, collection of the second]. St. Petersburg, Tipografiya II otdeleniya Sobstvennoy Yego Imperatorskogo Velichestva kantselyarii, 1845 Publ., Vol XIX, otdelenie pervoe, 1844 , no. 18398 , pp. 752-753.

14. Vysotnyy SPb [High-altitude St. Petersburg]. Kommersant. ru. Access mode: http://kommersant.ru/doc/2223512 (accessed 27.02.2017).

15. Sementsov S.V. Etapy formirovaniya prostranstvennoj sredy Sankt-Peterburga. Ch. 1. Istoricheskoe razvitie kvartalov $i$ ih reglamentatsiya [Stages of the formation of the spatial environment of St. Petersburg. Part 1. Historical development of quarters and their regulation]. Vestnik grazhdanskih inzhenerov [Bulletin of Civil Engineers], 2006, no. 2 (7), pp. 15-20.

16. Samin D.K. 100 velikikh arkhitektorov [100 great architects]. Moscow, Veche Publ., 2013, 592 p.

17. Shvidkovskiy D. Velikiy gorod Petra Velikogo [The Great City of Peter the Great]. Nashe nasledie [Our Heritage], 2003, no. 66, pp. 4-29. 
18. Borisova Ye.A. Raboty Domeniko Trezini po planirovke i zastroyke Strelki Vasil'yevskogo ostrova v Peterburge [Domenico Trezzini's work on the planning and development of the Spit of Vasilyevsky Island in St. Petersburg]. Russkoye iskusstvo veka. Materialy $i$ issledovaniya [Russian art of the century. Materials and research]. Moscow, 1973, pp. 20-37.

19. Kozhayeva L.B. Morfotipy zastroyki v teorii i na praktike [Building morphotypes in theory and practice]. Arkhitekturnyy vestnik [Architectural Herald], 2011, no. 4, pp. 43-47.
20. Kirikov B.M. Arkhitektura Peterburga kontsa XIX - nachala XX veka: Eklektika. Modern. Neoklassitsizm. [Architecture of St. Petersburg at the end of the XIX - beginning of the XX century: Eclecticism. Modern. Neoclassicism]. St. Petersburg, Kolo Publ., 2008, 448 p.

Лавров Леонид Павлович (Санкт-Петербург). Доктор архитектуры, профессор, член-корреспондент РААСН, член-корреспондент Германской академии градостроительства и планирования земель. Профессор-консультант ФГБОУ В0 «Санкт-Петербургский государственный архитектурно-строительный университет» (190005, Россия, Санкт-Петербург, 2-я Красноармейская ул., 4. СПбГАСУ). Эл. почта: leonid.lavrov@gmail.com.

Молоткова Елена Геннадьевна (Санкт-Петербург). Кандидат архитектуры, доцент. Заведующая кафедрой рисунка ФГБоу В0 «Санкт-Петербургский государственный архитектурно-строительный университет (190005, Россия, Санкт-Петербург, 2-я Красноармейская ул., 4. СПбГАСУ). Эл. почта: elena2255@yandex.ru.

Перов Федор Викторович (Санкт-Петербург). Кандидат архитектуры, доцент. Декан архитектурного факультета ФГБоУ В0 «Санкт-Петербургский государственный архитектурно-строительный университет (190005, Россия, Санкт-Петербург, 2-я Красноармейская ул., 4. СПбГАСУ). Эл. почта: f.perov@gmail.com.

Lavrov Leonid P. (St. Petersburg). Doctor of Architecture, Professor, Corresponding Member of RAACS, Corresponding Member of the German Academy of Urban and Land Use Planning (DASL). Professor-Consultant at the Saint Petersburg State University of Architecture and Civil Engineering (4 2nd Krasnoarmeyskaya st., St. Petersburg, Russia, 190005. SPSUACE). E-mail: leonid. lavrov@gmail.com.

Molotkova Elena G. (St. Petersburg). Candidate of Architecture, Associate Professor. Head of the Department of Drawing at the Saint Petersburg State University of Architecture and Civil Engineering (4 2nd Krasnoarmeyskaya st., St. Petersburg, Russia, 190005. SPSUACE). E-mail: elena2255@yandex.ru.

Perov Fedor V. (St. Petersburg). Candidate of Architecture, Associate Professor. Dean of the Faculty of Architecture of Petersburg State University of Architecture and Civil Engineering, head of the Department of Architectural Design at the Saint Petersburg State University of Architecture and Civil Engineering (4 2nd Krasnoarmeyskaya st., St. Petersburg, Russia, 190005. SPSUACE). E-mail: f.perov@gmail.com. 